\title{
CORRESPONDENCE
}

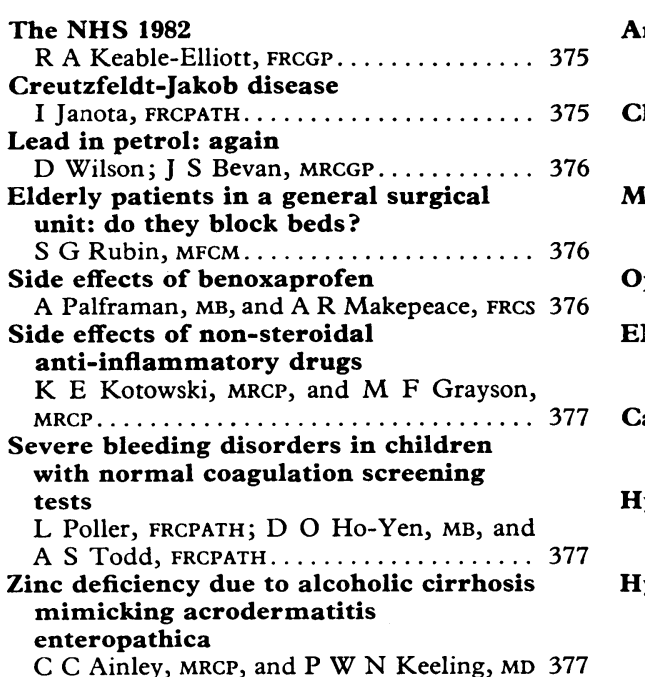

Aryl hydrocarbon hydroxylase and psoriasis

M D Rawlins, FRCP, and S Shuster, FRCP.. 378 Changes in home visiting and night and weekend cover: the patient's view

M G Jacoby, MB............... 378

Multiple general anaesthesia with

Althesin

J M Cundy, Ffarcs; F F Casale, fFarcs. . 378

p-Site and the DHSS

T S Warrender, мB............. 378

ENT problems and the general

practitioner

R P Morton, FRACS. .

ase clustering in pityriasis rosea:

support for role of an infective agent

P M Gaylarde, BSC.............. 379

Hypnotherapy for incontinence caused

by the unstable detrusor

G M Sole, FRCS, and others.

......... 379

hypocalcaemia occurring during

cancer chemotherapy

J P Monson, MRCP, and J J Bolger, FRCR. . 379
Strengths and weaknesses of British

medicine

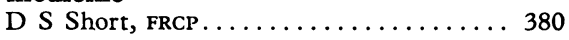

Prudent diet: effect on moderately

severe hyperlipidaemia

K J Cullen, FRCPED, and N S Stenhouse. . 380

Unusual complication of perforated appendix

Z H Krukowski, FRCSED, and N A Matheson,

FRCS; H J Thomson, FRCS, and W S

McKerrow, Frcs.............. 380

Anaesthesia and manpower proposals

R S Atkinson, FFARCS, and others...... 380

The distinction awards system in

England and Wales 1980

J G Benstead, FRCPATH. .

Fees for cervical smears

R M E Stone, MRCGP............. 381

Points Give cyclists room to move (F N

Leach; H M Rhoden; R Caplan; R G H

Wade $\ldots \ldots \ldots \ldots \ldots \ldots \ldots \ldots \ldots 1$

We may return unduly long letters to the author for shortening so that we can offer readers as wide a selection as possible. We receive so many letters each week that we have to omit some of them. Letters should be typed with double spacing between lines and must be signed personally by all their authors, who should include their degrees. We cannot acknowledge their receipt unless a stamped addressed envelope or an international reply coupon is enclosed.

\section{The NHS 1982}

SIR,-This is the story of two patients of mine recently referred to outpatients at my local hospital. The first was to the skin clinic. I duly received a courteous but unhelpful letter from the SHO. The patient in fact never saw the consultant, though the condition was not a particularly serious one.

Patient number two has just written to me as follows: "Further to my consultation with you on 15 June I went to make an appointment at the hospital and was told that it would not be for at least three months. Therefore I have decided to see another surgeon privately. Thank you for your advice."

The first consultant is so genuinely overworked that new patients have to be seen by SHOs. The second consultant sees all new patients himself, but they have to wait three months. Instances like this, everyday occurrences in general practice, bear out the underfunding of the NHS commented on by the Chairman of the Council in his address at the ARM. This is not the health service the patients expect, nor is it the health service the profession would wish to provide.

TONy KeABLE-ELLiotT

High Wycombe,
Bucks HPI4 3TG

\section{Creutzfeldt-Jakob disease}

SIR,-I believe that the anxieties about the possibility of infection by patients with Creutzfeldt-Jakob disease ( 5 June, $\mathrm{p}$ 1658) are not entirely rational; what anxiety is ever rational? Contrary to what Dr P O Behan writes, the recommendations of the Advisory Group on the Management of Patients with
Spongiform Encephalopathy (CreutzfeldtJakob Disease), ${ }^{1}$ proved or unproved, will not allay present anxieties, but if anything will nurture quite an unnecessary concern-in doctors, who at least should know better, and, what is worse, in the relatives of all sorts of patients. More generally, I do not believe that patients with proved Creutzfeldt-Jakob disease are more infectious than patients with schizophrenia, hypertension, cancer, or Pick's disease.

The very rare Creutzfeldt-Jakob disease may be due-as Gajdusek put it-to "something new to microbiology," but it is not dangerous in any way comparable to any infectious conditions in groups $\mathrm{B}_{1}$ or $\mathrm{B}_{2}$ of the Code of Practice for the Prevention of Infection in Clinical Laboratories and Post Mortem Rooms. ${ }^{2}$

If the rare dementing Creutzfeldt-Jakob disease normally presents between the human ages of 40 and 60 years, what are the clinical similarities to kuru as it used to be in New Guinea in young mothers and children in the Fore tribe, or to scrapie in sheep? It is true that Creutzfeldt-Jakob disease may be clinically confused with a host of other conditions, but Alzheimer's disease, for example, is so rarely accompanied by muscle atrophy and fasciculation that most doctors would never have encountered such a case. The impression that the clinical picture of Creutzfeldt-Jakob disease is so characteristic that the dearth of diagnostic support from laboratory investigations is of little concern is naive. Neuropathological examination of a brain biopsy specimen, which has become very rare, or of the brain at necropsy (and the transmission to animals) is still essential to confirm, or often enough, to refute the diagnosis. It is an exaggeration to stress "intense gliosis" among the microscopical features. I have examined several dozen cases, and the gliosis varies; sometimes it is certainly not what a neuropathologist would call "intense."

The transmission of Creutzfeldt-Jakob disease to monkeys is a fact, as is the exceptional transmission from patient to patient in the course of neurosurgery. The reference to a neurosurgeon with Creutzfeldt-Jakob disease, however, is not evidence that he caught it in the course of his (paediatric) practice. On what authority are the recommendations "mandatory" for some and why should psychiatrists, who unlike most other people may occasionally actually encounter a case of Creutzfeldt-Jakob disease, just "be aware" of the report?

Corsellis very cautiously concluded his review of the subject" : "The disease, is of course, dangerous to the patient for, as far as is known, it is virtually always fatal. On the other hand, if the evidence has been correctly assessed in the present review, we should not be brought to a standstill by the fear of crossinfection so rare in man that is has never yet been shown to occur other than through surgery.... Obviously all reasonable precautions must be taken, and these may well be better defined as more is learned. In the meantime, it would be disastrous if work on cerebral degeneration, which has for so long been considered a barren field, should come to a halt just when it seems at last to be coming to life."

IVAN JANOTA

Institute of Psychiatry,

London SE5 8AF

${ }^{1}$ Advisory Group on the Management of Patients with Spongiform Encephalopathy (Creutzfeldt-Jakob Disease). Report to the Chief Medical Officers of the Department of Health and Social Security, the Scottish Home and Health Department, and the Code of practice for the prevention of infection Code of practice for the prevention of infection in clinical 1978 ${ }^{3}$ Corsellis JAN. Br $\mathcal{F}$ Psychiatry 1979;134:443-59. 